\title{
Leave me alone: solitary females attract more mates in a nocturnal insect
}

\section{Lehtonen, Topi Kasperi}

2020-08

Lehtonen , T K \& Kaitala , A L 2020 , ' Leave me alone: solitary females attract more mates in a nocturnal insect ' , Behavioral Ecology , vol. 31 , no. 4 , pp. 1040-1045 . https://doi.org/10.1093/beheco/araa049

http://hdl.handle.net/10138/330118

https://doi.org/10.1093/beheco/araa049

unspecified

acceptedVersion

Downloaded from Helda, University of Helsinki institutional repository.

This is an electronic reprint of the original article.

This reprint may differ from the original in pagination and typographic detail.

Please cite the original version. 
Leave me alone: solitary females attract more mates in a nocturnal insect

Short title: Lone females attract more males

Topi K. Lehtonen ${ }^{1,2} \&$ Arja Kaitala ${ }^{1,2}$

${ }^{1}$ Department of Ecology and Genetics, University of Oulu, Post Box 3000, 90014 Oulu, Finland

2 Tvärminne Zoological Station, University of Helsinki, J.A. Palménin tie 260, 10900 Hanko, Finland

Correspondence: topi.lehtonen@oulu.fi 


\section{Abstract}

2 Spatial distributions of sexual competitors and potential mating partners have a large

3 impact on sexual selection and mating systems. Typically, such effects are investigated

4 with regard to male aggregations. However, females may also need to compete for

5 mating opportunities. Here we investigated consequences of clustering and rival

6 attractiveness on female mate attraction success under field conditions in a nocturnal

7 beetle, the common glow-worm, Lampyrus noctiluca. We placed dummy females of

8 two glow intensity (attractiveness) levels either alone or in clusters of varying

9 attractiveness compositions. We found that by displaying alone rather than in a cluster,

10 females have a higher probability of mating and greater potential to exercise mate

11 choice. Within clusters, females of both attractiveness levels had the highest probability

12 of mating when having neighbours of only the less attractive type. These results show

13 that both the presence and attractiveness of rivals can strongly influence females' mate

14 attraction. The findings also suggest that the typical distribution of glowing females in

15 the wild is better explained by female than male benefits. Hence, the results highlight

16 the important links between spatial distribution of females, male mate searching and

17 sexual selection.

18

19 Keywords: aggregation, bioluminescence, female competition, neighbour effect, sex

20 role, sexual selection 


\section{INTRODUCTION}

22 Spatial clustering of both potential mates and sexual competitors is a key factor in the

23 distribution of mating success within populations. In particular, spacing of individuals

24 impacts both the tactics for mate searching (and sampling) and the intensity of

25 interactions between rivals (Emlen and Oring 1977; Ims 1988; Andersson 1994). In this

26 respect, the consequences of spatial distribution of sexual signallers may differ

27 depending on their attractiveness. For example, some empirical studies suggest that

28 when mates are located farther apart (or otherwise in a lower density), their mating

29 success is distributed more evenly, which may benefit less ornamented sexual signallers

30 (Palokangas et al. 1992; Shelly and Bailey 1992; Berglund 1995; Kokko and Rankin

31 2006; Dougherty and Shuker 2015). However, under a different set of circumstances,

32 less attractive individuals may benefit from forming a cluster (see Adams and Morse

33 2014; van Wijk et al. 2017) for example due to attraction of potential mates by a cluster

34 being more important than attractiveness of individuals within the cluster. In males,

35 mating success benefits from clustering may result in impressive lek aggregations

36 (Beehler and Foster 1988; Gibson et al. 1990).

37 Within a cluster, an individual's success may also depend on the attractiveness of its

38 neighbours. For example, comparatively unattractive individuals might benefit from

39 close associations with more attractive signallers due to an increased number of visits

40 by members of the opposite sex (Beehler and Foster 1988; Partecke et al. 2002), which

41 also increases the potential of weaker signallers to "steal" matings from attractive rivals

42 (Gross 1996). An alternative hypothesis asserts that by associating with comparatively

43 unattractive rivals, an individual might benefit by increasing its relative attractiveness to

44 prospective mates (Bateson and Healy 2005). For instance, larger fiddler crab, Uca 
mjoebergi, males may increase their mating success if managing to associate with smaller neighbours (Callander et al. 2011).

47 To date, our understanding of the consequences of clustering or neighbour attractiveness on the distribution of matings has largely been based on lekking species, in which large

49 clusters of males gather together. In contrast, less is known about the role of clusters and signalling neighbourhoods in species that do not form leks and especially when

51 females compete with other females for mate attraction. Such situations may arise especially when reproducing using only stored resources, i.e. in capital breeders

53 (Houston et al. 2007). Due to the finite resources being traded-off between different aspects of reproduction, capital breeding females may pay particularly high fecundity or other fitness costs from prolonged sexual signalling or self-maintenance. Indeed, mating quickly can increase their expected number of offspring (in Lampyridae: Wing 1989; Hopkins 2018) and they may therefore need to actively attract mates and even compete for matings, independent of whether their fitness increases with the number of matings. Hence, capital breeding can result in increased variation in female reproductive success and strong sexual selection on female traits related to mate attraction.

61 We assessed the roles of clustering and signalling neighbourhoods in mate attraction in

62 females of a nocturnal, capital breeding beetle, the common glow-worm, Lampyrus noctiluca. In particular, we used dummy females in the field to assess the competing 64 hypotheses of benefits from clustering (as in leks: Beehler and Foster 1988; Gibson et al. 1990) and the proximity of rivals impacting female mating success negatively (male examples: Arak et al. 1990; Wong et al. 2018). In addition, we tested how attractiveness

67 of rivals affects the probability of attracting a mate and the potential for exercising mate 68 choice. We expected opportunities for mate choice to be highest for solitary females and 
69 females with less attractive rivals. Finally, we hypothesised that if male body size

70 correlates with competitiveness (as in many species: Hunt et al. 2009), smaller males may be more likely to target female clusters or less attractive females within such clusters.

\section{MATERIALS AND METHODS}

\section{Study site and model species}

The study was conducted in the vicinity of Tvärminne Zoological Station, southern Finland $\left(59^{\circ} 50.7^{\prime} \mathrm{N} ; 23^{\circ} 15.0^{\prime} \mathrm{E}\right)$, during the glow-worm breeding season (June - early July) in 2019.

The common glow-worm is a nocturnal beetle species in which flightless females emit a continuous greenish glow during calm summer nights to attract flying, non-glowing males. Females that have a larger body size emit, on average, a brighter glow and are also more fecund (Hopkins et al. 2015). A brighter glow, in turn, is expected to be more efficient in attracting males (Hopkins et al. 2015). This is particularly relevant because adult glow-worms do not eat (i.e. are capital breeders) and therefore need to use resources gathered during the larval stage for reproduction. Any delays in mating decrease female fecundity and are therefore likely to be highly costly to the female reproductive success (Hopkins 2018). In other words, it should be advantageous for a female to mate as soon as possible. While multiple males sometimes arrive within a short period of time, and a majority of females succeed in attracting a mate during their first or second night of displaying, considerably longer mating lags are not rare and mating delays up to three weeks have been documented (Dreisig 1971; Tyler 2002; 
92 Hickmott \& Tyler 2011; personal observations). The female ceases to glow very soon

93 after succeeding to mate, typically with a single male, then lays her eggs and dies soon

94 after (Dreisig 1971; Tyler 2002; personal observations). Field observations suggest that

95 the successful male tends to guard the female until the morning (Tyler 2002; personal

96 observations), but it may potentially mate again at least during oncoming nights.

97 Glowing females are aggregated within good signalling habitats and areas, whereas

98 within such areas, their spatial distribution does not seem to be similarly aggregated. In

99 the local population, the distance between adjacent females was found to be an average

1004 metres, $>1$ metre in $79 \%$ of the assessed cases, and $\leq 0.50$ metres in slightly over $10 \%$

101 of the cases (Borshagovski et al. 2019). The realised distances between signalling

102 females may be affected by e.g. the population size, behavioural interactions among

103 females, suitable spots for mate attraction, and egg-laying opportunities within the 104 habitat

\section{Study design}

106 We tested female attractiveness with respect to different signalling neighbourhood

107 compositions in the field using dummy females that trapped males landing to mate. The

108 dummy females were constructed by slightly modifying the methods of Hopkins et al.

109 (2015). Briefly, each dummy female consisted of a plastic funnel trap (volume: 1 litre)

110 that had a green $5 \mathrm{~mm}$ light emitting diode (LED) mounted on the top and in the centre

111 of the funnel's mouth (Figure $1 a$ ). The peak emission wavelength of the LED was $\sim 560$

$112 \mathrm{~nm}$, mimicking the glow of a live female common glow-worm (Tyler 2002; De Cock

113 2004), and it was powered by two standard AA dry batteries (Figure 1a). We

114 constructed dummy females of two brightness and hence expected attractiveness

115 (Hopkins et al. 2015) levels. The glow intensity of the brighter female type (hereon:

116 "B") was controlled by wiring the LED with one $1000 \mathrm{ohm}$ resistor (resulting in the 
117 peak glow intensity of $\sim 0.13 \mu \mathrm{W} / \mathrm{nm}$ ). Each dummy female of the dimmer type (hereon:

118 "D") had its LED wired with four 1000 ohm resistors (peak glow intensity: $\sim 0.02$

$119 \mu \mathrm{W} / \mathrm{nm})$. Such a difference in relative brightness is easily visible to a human observer

120 and reflects the range seen among wild females in the local population (personal

121 observations).

122 Each dummy female was placed either on its own (B: $n=30 ; \mathrm{D}: n=30)$ or in a cluster

123 of four dummy females that were placed in the formation of a quadrate with $50 \mathrm{~cm}$ sides

124 (Figure $1 b ; n=57$ clusters that included 228 dummy females). To assess the effects of

125 different competitive neighbourhoods, we ran replicates with all possible combinations

126 of B and D dummy females. This allowed our female level analysis (see below for

127 details) to have the following four neighbourhood categories: no neighbours $(n=60)$,

128 all neighbours of the B type $(n=56)$, all neighbours of the D type $(n=56)$ and both

129 neighbour types present $(n=116$; Figure 1$)$.

130 There was no direct line of sight between any adjacent replicates and the minimum

131 distance between them was 100 metres. Each replicate lasted one night, and we ran $\sim 1$

132 replicate of each replicate type (range: 0 - 2) simultaneously, with the locations of

133 replicates relative to each other having been randomised using a random number

134 generator. The female dummies were set at 23:00 - 24:00 hours and then left out to

135 attract males for 130 - 180 minutes (depending on the night), which covered the entire

136 nightly glowing period of wild females and mate searching period of males at the

137 research site (personal observations). The surroundings of each replicate were checked

138 once or twice during the night to ensure that no other females were glowing in close

139 proximity. After a replicate was completed, the number of males trapped by the dummy

140 female was counted and, as a proxy of body size, the dorsal exoskeletal plate 
141 (pronotum) width of each male was later measured in the laboratory using a calliper.

142 The males were then marked and released back to the wild.

143 The above data were used, as follows, to assess how clustering and competitive

144 neighbourhood affect females' probability of mate attraction (during their first night of

145 signalling), their potential to be choosy, and phenotypes (body sizes) of the attracted

146 males.

147 Probability of attracting a mate

148 We used R 3.3.2 software (R Development Core Team) for all statistical analyses. First,

149 we ran a generalised mixed models ('lme4' package) with a binomial distribution to

150 assess whether or not a dummy female had managed to attract at least 1 male, i.e. using

151 the presence of at least one trapped male (possible values: $0 / 1$ ) as the response

152 variable. Dummy brightness (B / D) and neighbourhood category (solitary / all B

153 neighbours / all D neighbours / B and D neighbours present) were assigned as fixed

154 effects and "replicate ID" was added as a random effect to account for the non-

155 independence of dummy females within a replicate. We then proceeded with refitting

156 the model using $\chi^{2}$ - tests (as per Crawley 2007). In this regard, if the interaction was

157 found to be non-significant, the main effects were assessed from a model fitted without

158 it.

\section{Potential to be choosy}

160 As a proxy of a (dummy) female's opportunity to be choosy, we used the number of

161 attracted males. This assessment was conducted among the subset of dummy females

162 that had attracted at least 1 male. Here we assumed a Poisson distribution ('lme4'

163 package) as appropriate for count data that is not overdispersed (assessed as per Zuur et 
164 al. (2013)). We then applied the same fixed effects, a random effect, and refitting

165 procedure as described in the previous section.

\section{Male size}

167 With regard to male body size, we were interested in whether female clustering or

168 brightness affects the body size of attracted males. For example, if multiple males arrive 169 at the same time, small males might have higher chances of success when targeting less 170 attractive females or clusters of females (rather than solitary ones). Overall, the female

171 dummies captured 389 males. Of these, pronotum width data are missing for 9

172 individuals, 6 were recaptures from replicates run during previous nights and another 4

173 had been captured earlier (and then marked and released) in an unrelated experiment

174 conducted near the research station. All available data points were included in the data

175 analyses and the exclusion of the recaptures does not change the conclusions. We

176 applied a linear mixed effects model ('nlme' package) with male pronotum width as the

177 response variable and in other respects used the same variables and general approach as 178 described above.

\section{RESULTS}

\section{Probability of attracting a mate}

182 Overall, $47 \%$ (135 out of 288 ) of the dummy females, whether alone or in a cluster,

183 attracted at least 1 male. The interaction between female brightness and neighbourhood

184 type did not have a significant effect (mixed model, model comparison: $\chi^{2}=1.692, \mathrm{df}=$

$1853, P=0.64)$. A dummy female was more likely to attract a male when it was brighter

186 (mixed model, $\chi^{2}=13.11, \mathrm{df}=1, P<0.001$; Figure $2 a$ ). The neighbourhood also had a 
187 significant effect on the probability of attracting a mate (mixed model, overall

188 neighbour effect: $\left.\chi^{2}=15.50, \mathrm{df}=3, P=0.0014\right)$. In particular, mate attraction

189 probability was the highest for solitary females (solitary: 63\% versus combined

190 probability for clusters: $43 \%$, implying a significant difference at $\alpha=0.01$ ), with the

191 probability being significantly lower in other neighbourhood types except for the one

192 with only D (dimmer) neighbours (Figure $2 b$, Table $1 a$ ). Within clusters, mating

193 probability was therefore the highest when the focal dummy female had only D

194 neighbours (Figure $2 b$, Table $1 a$ ) and it was the lowest when both types of neighbours

195 were present (Figure 2b, Table 1a).

\section{Potential to be choosy}

197 Regarding female dummies that attracted at least one male, the interaction effect

198 between brightness and neighbourhood category on the number of attracted males was

199 not significant (mixed model, model comparison, $\chi^{2}=3.084, \mathrm{df}=3, P=0.38$ ). As with

200 the probability to mate, B dummy females attracted higher numbers of males than D

201 ones (mixed model, $\chi^{2}=7.763, \mathrm{df}=1, P=0.0053$; Figure $3 a$ ). In addition,

202 neighbourhood had a significant effect on the number of attracted males (mixed model,

$203 \chi^{2}=32.33, \mathrm{df}=3, P<0.001 ;$ Figure $3 a$ ), with solitary females attracting a higher

204 number of males than any of the clustered neighbourhood types (Figure $3 b$, Table $1 b$ )

205 and the different clustered neighbourhoods not significantly differing from each other

206 (Figure $3 b$, Table $1 b$ ). It is worth noting that the number of males attracted by clusters

207 of four with at least one successful dummy female $(5.0 \pm 0.6[$ mean $\pm \mathrm{SE}], n=44$

208 clusters) was not significantly different from the number of males attracted by solitary

209 female dummies attracting at least one male $(4.4 \pm 0.6, n=38)$ (Wilcoxon rank sum test

210 with continuity correction, $W=902, P=0.54)$. This conclusion remains the same if all

211 dummies (i.e. also non-successful ones) are included. 


\section{Male size}

213 Body size of the attracted males did not significantly differ regarding any of the

214 assessed variables (Linear mixed model, all $P>0.10$ ).

\section{DISCUSSION}

217 We found that, in accordance with the prior expectation (Hopkins et al. 2015), brighter

218 dummy females were more likely to attract males than dimmer ones. This effect was

219 independent of the neighbourhood types. Notably, independent of female brightness

220 (attractiveness), a higher percentage of solitary than clustered females attracted a mate,

221 with solitary females also attracting higher total numbers of males. The results also

222 show that when females are in clusters, their neighbourhood is important: female success in attracting at least one mate was the highest when the neighbourhood only consisted of females of the dimmer (D) category and it was the lowest when the neighbourhood consisted of a mixture of both female types (B and D).

226 Some previous studies have suggested that males of non-lekking species should

227 advertise relatively far apart from their rivals. For instance in bushcrickets, Tettigonia

228 viridissima, males were less successful in attracting females when clustered than when regularly spaced within an experimental arena (Arak et al. 1990). In the European tree frog, Hyla arborea, the ability of mate sampling females to discriminate male acoustic

231 signals improved with increased separation of the speakers producing the male call

232 (Richardson and Lengagne 2010). These species, however, employ acoustic sexual

233 signals, which may be more prone to signal interference than species that rely mostly on

234 visual signals. Our results show that the benefit of physical distance from rivals does 
apply also when females compete with other females for mating opportunities using a

236 visual signal. In particular, a larger proportion of glow-worm female dummies attracted 237 a male when alone than when in a cluster, with this effect being similar for females of 238 both brightness (attractiveness) levels. Among the females that succeeded in attracting a 239 male, solitary females attracted larger numbers of males than clustered females. Indeed, 240 the numbers of males attracted by four clustered female dummies together were not 241 significantly higher than those attracted by solitary female dummies, implying that the benefits of solitary mate attraction are high in this system. We note the possibility that if

243 the local male density is exceptionally high, males might arrive in short enough

244 succession (before the female glow signal has faded) to sexually harass solitary females 245 especially.

246 In many systems, female reproductive success does not significantly increase with the 247 number of matings (e.g. Parker 2006). This is also likely to be the typical case in capital breeders such as glow-worms, which nevertheless are likely to benefit from mating quickly: mating delays can reduce their fecundity (Wing 1989; Hopkins 2018). The result that solitary females mate quicker also helps to explain why females in the wild are not more commonly clustered in smaller spatial scales. From the male perspective, our results imply that a solitary female is more likely to attract rival males, inducing a higher probability of failure to mate after finding a female due to male-male competition. After mating, the glow-worm male usually guards the female (Tyler 2002; personal observations), but a cluster of females might nonetheless provide the male more opportunities to compare females or to mate with additional females later. If some

257 males are indeed able to remate later without getting markedly sperm depleted, for

258 females, the difference between signalling alone versus in a cluster may be smaller than our results suggest. However, the scope for males to remate, at least during the same 
260 night, seems to be limited in this system (Tyler 2002; personal observations). Therefore,

261 our results indicate that the system is female rather than male driven: females benefit

262 from signalling separately, whereas males should benefit from arriving at clusters of

263 signalling females.

264 In the competitive situation within a cluster, differences in individuals' mate attraction

265 abilities may be important. We found evidence for the cost of having neighbours being

266 the lowest (i.e. mating probability being the highest) when all neighbours were of the

267 lower attractiveness (brightness) category. By showing that the neighbourhood does

268 affect attractiveness of an individual, the results suggest that an active choice of the

269 social environment may pay off (see Laland et al. 1999; Ryder et al. 2009). Previous

270 studies have found, for instance, that less attractive male house finches, Carpodacus

271 mexicanus, can improve their pairing success by changing to a new social group (Oh

272 and Badyaev 2010). Glow-worm females, in turn, have been found to move away from

273 a particularly bright (dummy) rival (Borshagovski et al. 2019). Females of glow-worms

274 and other capital breeding species may also face a trade-off between mating as quickly

275 as possible (to optimise fecundity) and exercising mate choice, with larger (and hence

276 likely brighter) females being in a better position to pay the costs of any mating delays

277 (Hopkins 2018). In the current study, a neighbourhood consisting of both bright and dim

278 rivals was the least favourable. Such a pattern could be due to, for example, a

279 heterogeneous female cluster being less detectable or attractive to males, providing an

280 interesting avenue for future research. Furthermore, clusters of four consisting solely of

281 bright (B) females attracted more males than clusters with only dim (D) females, which

282 increases the observed success of females in the "B neighbours only" category and

283 decreases the detected benefit of having only D neighbours. 
284 We cannot rule out a completely passive mate attraction (Arak 1988) taking place in this

285 system, with males simply mating with the first female they happen to detect. Such a

286 mating pattern may result in an overall advantage for B females and within groups an

287 advantage to females that have only D neighbours. Neither is the scenario in direct odds

288 with our finding that a greater brightness did not always ensure an advantage, with D

289 females attracting some (albeit on average a lower number of) males even when in the

290 same cluster with one or multiple B rivals. Regardless of whether males exert active or

291 passive mate choice, our results suggest that selection favours females that glow alone

292 rather than in groups and within a group females should be better off signalling in the

293 absence of any attractive neighbours.

294 To conclude, in this study we have shown that by displaying alone rather than in

295 clusters, females, independent of their attractiveness, have a higher probability of

296 mating quickly and have a greater potential to be choosy. The results also show that

297 within clusters, the most favourable neighbourhood may be the one that exclusively has

298 neighbours of lower level of attractiveness. Hence, the results strengthen our

299 understanding of the relationships between spatial distribution, sexual competition and

300 mating success, showing their importance even when females compete with other

301 females.

303 Funding

304 The work was supported by the Academy of Finland [grant number 294664 to AK]. 
307 We are grateful to Anna-Maria Borshagovski, Christina Elgert, Juhani Hopkins, Timo

308 Piepponen and Otso Valkeeniemi for their help with the fieldwork preparations, to

309 Natarsha Babic and Timo Piepponen for assistance with data gathering, Ulrika

310 Candolin, Juhani Hopkins and anonymous reviewers for insightful comments on earlier

311 versions of the text, Maria-Elena Bernal for checking the grammar, and the staff of

312 Tvärminne Zoological Station for logistic support.

314 Data Accessibility: Analyses reported in this article can be reproduced using the data

315 provided by Lehtonen and Kaitala (2020).

316

317 REFERENCES

318 Adams SA, Morse DH. 2014. Condition-dependent mate choice of a parasitoid wasp in 319 the field. Anim Behav. 88:225-232.

320 Andersson M. 1994. Sexual selection. Princeton, NJ: Princeton University Press.

321 Arak A. 1988. Female mate selection in the natterjack toad: active choice or passive 322 attraction? Behav Ecol Sociobiol. 22:317-327.

323 Arak A, Eiriksson T, Radesäter T. 1990. The adaptive significance of acoustic spacing

324 in male bushcrickets Tettigonia viridissima: a perturbation experiment. Behav Ecol

325 Sociobiol. 26:1-7.

326 Bateson M, Healy SD. 2005. Comparative evaluation and its implications for mate

327 choice. Trends Ecol Evol. 20:659-664. 
328 Beehler BM, Foster MS. 1988. Hotshots, hotspots, and female preference in the

329 organization of lek mating systems. Am Nat. 131:203-219.

330 Berglund A. 1995. Many mates make male pipefish choosy. Behaviour. 132:213-218.

331 Borshagovski A-M, Baudry G, Hopkins J, Kaitala A. 2019. Pale by comparison:

332 competitive interactions between signaling female glow-worms. Behav Ecol. 30:20-26.

333 Callander S, Jennions MD, Backwell PRY. 2011. Female choice over short and long

334 distances: neighbour effects. Behav Ecol Sociobiol. 65:2071-2078.

335 Crawley MJ. 2007. The R Book. Chichester, UK: John Wiley \& Sons Ltd.

336 De Cock R. 2004. Larval and adult emission spectra of bioluminescence in three

337 European firefly species. Photochem Photobiol. 79:339-342.

338 Dougherty LR, Shuker DM. 2015. The effect of experimental design on the

339 measurement of mate choice: a meta-analysis. Behav Ecol. 26:311-319.

340 Dreisig H. 1971. Control of the glowing of Lampyris noctiluca in the field (Coleoptera:

341 Lampridae). J Zool. 165:229-244.

342 Emlen ST, Oring LW. 1977. Ecology, sexual selection, and the evolution of mating

343 systems. Science. 197:215-223.

344 Gross MR. 1996. Alternative reproductive strategies and tactics: diversity within sexes.

345 Trends Ecol Evol. 11:92-98. 
346 Hickmott W, Tyler J. 2011. Seasonal variation in the female display period of the glow-

347 worm Lampyris noctiluca L. Lampyrid. 1:14-21.

348 Hopkins J. 2018. The costs and consequences of female sexual signals. ( $\mathrm{PhD}$ Thesis)

349 Oulu, Finland: University of Oulu.

350 Hopkins JP, Baudry G, Candolin U, Kaitala A. 2015. I'm sexy and I glow it: Female 351 ornamentation in a nocturnal capital breeder. Biol Lett. 11:8-11.

352 Houston AI, Stephens PA, Boyd IL, Harding KC, Mcnamara JM. 2007. Capital or

353 income breeding? A theoretical model of female reproductive strategies. Behav Ecol. $354 \quad 18: 241-250$.

355 Hunt J, Breuker CJ, Sadowski JA, Moore AJ. 2009. Male-male competition, female 356 mate choice and their interaction: determining total sexual selection. J Evol Biol. 22:1335726.

358 Ims RA. 1988. The potential for sexual selection: effect of sex ratio and spatiotemporal 359 distribution of receptive females. Evol Ecol. 2:338-352.

360 Kokko H, Rankin DJ. 2006. Lonely hearts or sex in the city? Density-dependent effects 361 in mating systems. Phil Trans R Soc B. 361:319-334.

362 Laland KN, Odling-Smee FJ, Feldman MW. 1999. Evolutionary consequences of niche 363 construction and their implications for ecology. Proc Natl Acad Sci USA. 96:1024236410247. 
365 Lehtonen TK, Kaitala A. 2020. Leave me alone: solitary females attract more mates in a

366 nocturnal insect. Dryad, Dataset, https://doi.org/10.5061/dryad.bg79cnp7v

367 Oh KP, Badyaev AV. 2010. Structure of social networks in a passerine bird:

368 consequences for sexual selection and the evolution of mating strategies. Am. Nat.

369 176:E80-E89.

370 Palokangas P, Alatalo RV, Korpimäki E. 1992. Female choice in the kestrel under

371 different availability of mating options. Anim Behav. 43:659-665.

372 Parker GA. 2006. Sexual conflict over mating and fertilization: an overview. Phil Trans

373 R Soc B. 361:235-259

374 Partecke J, von Haeseler A, Wikelski M. 2002. Territory establishment in lekking

375 marine iguanas, Amblyrhynchus cristatus: support for the hotshot mechanism. Behav

376 Ecol Sociobiol. 51:579-587.

377 Richardson C, Lengagne T. 2010. Multiple signals and male spacing affect female

378 preference at cocktail parties in treefrogs. Proc R Soc B. 277:1247-1252.

379 Ryder TB, Parker PG, Blake JG, Loiselle BA. 2009. It takes two to tango: reproductive

380 skew and social correlates of male mating success in a lek-breeding bird. Proc R Soc B.

$381 \quad 276: 2377-2384$.

382 Shelly TE, Bailey WJ. 1992. Experimental manipulation of mate choice by male

383 katydids: the effect of female encounter rate. Behav Ecol Sociobiol. 30:277-282.

384 Tyler J. 2002. The glow-worm. Kent, UK: Lakeside Printing Ltd. 
385 van Wijk M, Heath J, Lievers R, Schal C, Groot AT. 2017. Proximity of signallers can

386 maintain sexual signal variation under stabilizing selection. Sci Rep. 7:18101.

387 Wing SR. 1989. Energetic costs of mating in a flightless female firefly, Photinus

388 collustrans (Coleoptera: Lampyridae). J lnsect Behav. 2:841-847.

389 Wong BBM, Lehtonen TK, Lindström. 2018. Spatial and temporal patterns of nest

390 distribution influence sexual selection in a marine fish. Oikos. 127:1104-1112.

391 Zuur AF, Hilbe JM \& Ieno EN. 2013. A beginner's guide to GLM and GLMM with R:

392 A frequentist and Bayesian perspective for ecologists. Newburgh, UK: Highland

393 Statistics. 
395 Table 1. Pair-wise differences between neighbourhood types. B and D refer to the two

396 brightness levels. In both panels, (a) and (b), the upper right part gives $z$ values

397 (provided by a mixed model described in the methods) and the lower left part gives the

398 matching $P$ values

\begin{tabular}{|c|c|c|c|c|c|}
\hline \multirow{6}{*}{$\begin{array}{l}\text { (a) Mating } \\
\text { probability }\end{array}$} & & Solitary & Only B & Only D & Both B and D \\
\hline & Solitary & & 2.243 & 0.442 & 3.262 \\
\hline & Only B & 0.025 & & 1.665 & 0.734 \\
\hline & Only D & 0.66 & 0.096 & & 2.576 \\
\hline & Both B and D & 0.0011 & 0.46 & 0.010 & \\
\hline & & Solitary & Only B & Only D & Both B and D \\
\hline \multirow{4}{*}{$\begin{array}{l}\text { (b) Number of } \\
\text { males }\end{array}$} & Solitary & & 3.638 & 3.672 & 5.929 \\
\hline & Only B & $<0.001$ & & 0.197 & 1.397 \\
\hline & Only D & $<0.001$ & 0.84 & & 1.756 \\
\hline & Both B and D & $<0.001$ & 0.16 & 0.079 & \\
\hline
\end{tabular}




\section{Figure legends}

400

$401 \quad$ Figure 1

402 (a) A female dummy, i.e. a funnel trap equipped with a green LED on top, as a

403 schematic presentation (left panel) and as seen during night time from above (right

404 panel). (b) Dummy females were placed either in clusters of four or singly. (c) Within a

405 cluster, the neighbours were either all of the brighter type (darker orbs, left cluster) all

406 dim (paler orbs, right cluster) or a mix of the two neighbour types (lower middle

407 cluster). In these examples, the focal dummy female, denoted with a dashed ring, was of

408 the brighter type

409

$410 \quad$ Figure 2

411 The percentage of dummy females that attracted at least 1 male with regard to $(a)$

412 brightness and $(b)$ neighbourhood categories. In $(b)$, columns without a letter in

413 common are significantly different (mixed model, $\alpha=0.05$; Table $1 a$ ), and the clustered

414 neighbourhood categories are coloured. The error bars show 95\% confidence intervals.

415 Sample size are given above each column

416

417 Figure 3

418 The number of males attracted by those female dummies that attracted at least 1 male,

419 with regard to $(a)$ female dummy brightness and $(b)$ neighbourhood categories (those

420 without a letter in common are significantly different; mixed model, $\alpha=0.05$, Table

$421 \quad 1 b)$. Sample size are given above each column 